\title{
Carcinoid case presentation and discussion: the American perspective
}

\author{
$R$ R P Warner
}

Department of Medicine, Gastrointestinal Division, The Mount Sinai School of Medicine, One Gustave L Levy Place, New York, New York 10029, USA

(Requests for offprints should be addressed to R R P Warner; Email: rwarner—md@carcinoid.org)

\begin{abstract}
The rationale underlying an aggressive approach in the management of some carcinoid patients is explained and illustrated by the presented case of a middle-aged man with advanced classic typical midgut carcinoid. The patient exhibited somatostatin receptor scintigraphy-positive massive liver metastases, carcinoid syndrome, severe tricuspid and pulmonic cardiac valve disease with congestive heart failure, ascites and malnutrition. He had been treated for several years with supportive medications and biotherapy including octreotide and alpha interferon but his tumor eventually progressed and his overall condition was markedly deteriorated when he first sought more aggressive treatment. This consisted of prompt replacement of both tricuspid and pulmonic valves, followed by hepatic artery chemoembolus (HACE) injection and then surgical tumor debulking including excision of the primary tumor in the small intestine. In addition, radiofrequency ablation was utilized to reduce the volume of metastases in the liver. Prophylactic cholecystectomy was also performed and a biopsy of tumor was submitted for cell culture drug resistance testing. This was followed by systemic chemotherapy utilizing the drug (docetaxel) which the in vitro studies suggested as most likely to be effective. His excellent response to this succession of treatments exemplifies the successful application of aggressive sequential multi-modality therapy.
\end{abstract}

Endocrine-Related Cancer (2003) 10 489-496

\section{Introduction}

I have been requested to present a case report to illustrate how carcinoid is treated in the United States. That is easy to do, but it is also difficult since there is no uniformly practiced standard approach being followed in the United States for the management of these patients. Still adhering to the original description of carcinoid as a benign neoplasm, or at least one with extremely slow growth (Oberndorfer 1907), there is a widely prevalent conservative attitude of 'wait and see', waiting for the patient to become very symptomatic and/or the tumor to become clearly larger (Öberg 2000), and then to treat as minimally as possible. These tumors vary widely in their aggressiveness and production of symptoms, with many growing very slowly but others having a more malignant course (Jensen 2000). Although this conservative approach works well in many cases it must not be generalized and applied to all since it has become apparent over the past decade that carcinoid is not as completely benign as it was originally thought to be (Modlin et al. 2003). At the other end of the management spectrum is the aggressive proactive approach, which is gaining adherence as it becomes noted that properly selected patients fare better with earlier and sometimes aggressive treatment (Öberg 1998). This observation also applies to many far-advanced cases previously relegated to simple non-interventional palliative care. With this spectrum of management in mind I am presenting a case of very far-advanced metastatic midgut carcinoid with carcinoid syndrome and severe cardiac complications responding very well to aggressive sequential treatment with multiple modalities and exemplifying the benefits of such an approach.

\section{Case report}

This 55-year-old Caucasian male postal worker had been in good health, except for mild chronic hypertension, until 1999 when he noted the onset of facial flushing and mild pitting edema of his feet. Physical examination disclosed an enlarged hard nodular non-tender liver. CT scan of the abdomen revealed multiple small nodules and several very large confluent lesions in both lobes of the liver (Fig. 1). Needle biopsy was interpreted as typical carcinoid. A barium contrast study of the small intestine revealed no lesions. Twentyfour hour urinary 5-hydroxyindoleacetic acid (5-HIAA) was 


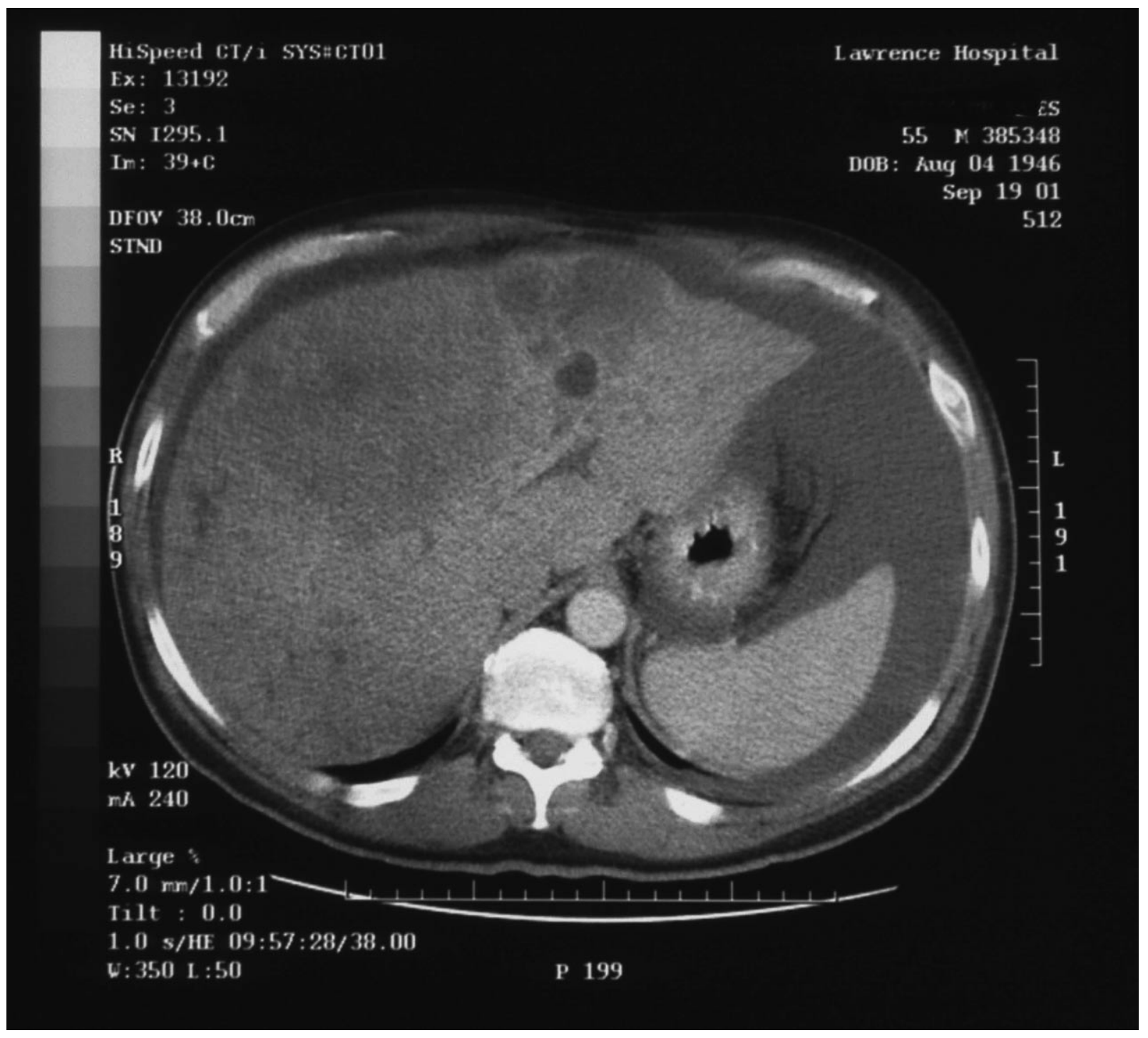

Figure 1 CT scan of abdomen, 2 September 2001; prior to aggressive treatment.

markedly elevated at $230 \mathrm{mg}$ (normal <6). Blood serotonin was also increased with a value of $702 \mathrm{ng} / \mathrm{ml}$ (normal <80) (Table 1). An echocardiogram revealed marked tricuspid regurgitation and pulmonic hypertension.

Treatment with s.c. injections of octreotide was started and rapidly switched to monthly i.m. injections of $30 \mathrm{mg}$ of the long-acting formulation. The flushing was relieved.

He had been maintained on low-dose chronic diuretic (hydrochlorothiazide). This was increased and spironalactone was added. Additional medications consisted of metoprolol and potassium chloride. Alpha interferon treatment was initiated using 3 million units by s.c. injection three times a week.
His pedal edema cleared and he remained comfortable for approximately 1 year but then ascites and non-productive cough occurred and he required large volume abdominal paracentesis on three occasions. He became progressively weaker and also began to note mild diarrhea. Flushing returned. Therefore in search of additional treatment the patient consulted us on 2 January 2002.

Physical examination revealed him to be a gaunt, wasted, chronically ill-appearing middle-aged white male with a markedly red facial flush. The skin was dry. He was $186 \mathrm{~cm}$ in height and weighed $81 \mathrm{~kg}$. Blood pressure was 110/80 and heart rate was 76 beats per minute and was regular. Neck veins were distended and pulsatile. The lungs were clear. 
Table 1 Pertinent laboratory tests

\begin{tabular}{|c|c|c|}
\hline Test & $\begin{array}{l}\text { Before aggressive treatment } \\
\text { (January 2002) }\end{array}$ & $\begin{array}{l}\text { After aggressive treatment } \\
\text { (March 2003) }\end{array}$ \\
\hline \multicolumn{3}{|l|}{ Urine } \\
\hline 5-HIAA & 230 mg/24 h (normal <6) & - \\
\hline \multicolumn{3}{|l|}{ Blood } \\
\hline Serotonin & 702 ng/ml (normal <180) & $396 \mathrm{ng} / \mathrm{ml}$ \\
\hline Chromogranin-A & 716 ng/ml (normal <39) & $615 \mathrm{ng} / \mathrm{ml}$ \\
\hline Atrial natriuretic factor & $180 \mathrm{pg} / \mathrm{ml}$ (normal 20-77) & - \\
\hline Blood urea nitrogen & 24 mg/dl (normal 7-25) & - \\
\hline Creatinine & 0.9 mg/dl 9Normal 0.5-1.4) & - \\
\hline Electrolytes & Normal & - \\
\hline Total bilirubin & 0.77 mg/dl 9normal 0.2-1.5) & $0.81 \mathrm{mg} / \mathrm{dl}$ \\
\hline Alkaline phosphatase & $170 \mathrm{U} / \mathrm{l}$ (normal 20-25) & $152 \mathrm{U} / \mathrm{l}-$ \\
\hline$\gamma$-Glutamyltransferase & $106 \mathrm{U} / \mathrm{l}$ (normal 2-80) & - \\
\hline Alanine aminotransferase & $35 \mathrm{U} / \mathrm{l}$ (normal 2-60) & $35 \mathrm{U} / \mathrm{l}$ \\
\hline Aspartate aminotransferase & 33 U/I (normal 2-50) & $35 \mathrm{U} / \mathrm{l}$ \\
\hline Albumin & $2.9 \mathrm{~g} / \mathrm{dl}$ (normal 3.5-4.9) & $3.8 \mathrm{~g} / \mathrm{dl}$ \\
\hline White blood cells & $4600 \times 10^{9} \mathrm{cells} / \mathrm{l}($ normal $4.6-11.0$ ) & - \\
\hline Hematocrit & $42.3 \%$ (normal $40-52 \%$ ) & - \\
\hline
\end{tabular}

A prominent systolic ejection murmur was heard along the left sternal border and the abdomen was soft but markedly distended by ascites. A $3 \mathrm{~cm}$ slightly tender nodular mass was felt in the mid-epigastrium. The hands and feet had a dusky cyanotic appearance and one plus pitting edema of both feet was present.

A new CT scan of the abdomen with contrast showed a markedly enlarged liver with large bilobar confluent metastases and multiple small lesions. A new small bowel barium contrast X-ray series showed a filling defect in the distal ileum, which narrowed the lumen of the intestine to approximately $3 \mathrm{~mm}$ (Fig. 2). An octreoscan showed multiple foci of isotope concentration in the liver only.

\section{Management}

The patient's prior medications were continued and low-dose niacin ( $25 \mathrm{mg}$ p.o. b.i.d.) was added. Repeat cardiac evaluation was obtained and confirmed the presence of severe tricuspid regurgitation and pulmonic stenosis. The patient was felt to be in marked right heart failure and the urgency of his cardiac disease was considered to supercede any consideration of cytoreductive treatment. Furthermore he was felt to be unable to tolerate any attempt at anti-tumor treatment. Accordingly, on 15 February 2002 he underwent cardiac surgery consisting of replacement of both the tricuspid and pulmonic valves with bovine pericardial prostheses and he also underwent closure of a patent foramen ovule discovered at that surgery.

He experienced a remarkably rapid improvement following this surgery and noted $15 \mathrm{~kg}$ weight loss, clearing of his pedal edema and cough, and decrease in his ascites over the next 3 weeks. However, 1 month following the surgery (15 March 2002) his blood chromogranin-A had risen to 1320 $\mathrm{ng} / \mathrm{ml}$ and the chromogranin-A content of his residual ascitic fluid was $716 \mathrm{ng} / \mathrm{ml}$. The ratio between the concentration of this marker in each of these fluids was interpreted as indicating the ascites was due to a hemodynamic disturbance rather than to direct tumor exudation. Therefore no additional treatment was given beyond continuation of his diuretics, octreotide and the same pre-operative medications. Over the next 2 months his ascites totally receded.

In September of 2002 he was started on a series of three HACE injection treatments which were carried out monthly. Injected drugs consisted of cisplatin, doxorubicin, mitomycin, X-ray contrast and microspheres (embospheres) which were all injected simultaneously into different segments of the liver on each of the three treatment procedures. He tolerated this very well and in December of 2002 was finally submitted for laparoscopic abdominal surgery. At that time the segment of terminal ileum containing the primary carcinoid was resected and a new biopsy of tumor was obtained for histological studies and also for in vitro cell culture drug resistance testing. Also, a prophylactic cholecystectomy was performed along with ultrasonography-guided radiofrequency ablation of a $4 \mathrm{~cm}$ metastasis and two smaller adjacent ones in segment 4 of the liver. Supplemental octreotide was administered perioperatively and the patient tolerated the entire procedure very well. He was fully ambulatory and eating a regular diet on his 4 th postoperative day.

Histology of the biopsied tumor was read as typical carcinoid with a low proliferation index $(\mathrm{MIB}-1<1 \%)$. Stains for p53 were negative. Cell culture drug resistance testing indicated that in vitro the tumor was sensitive to docetaxel. 


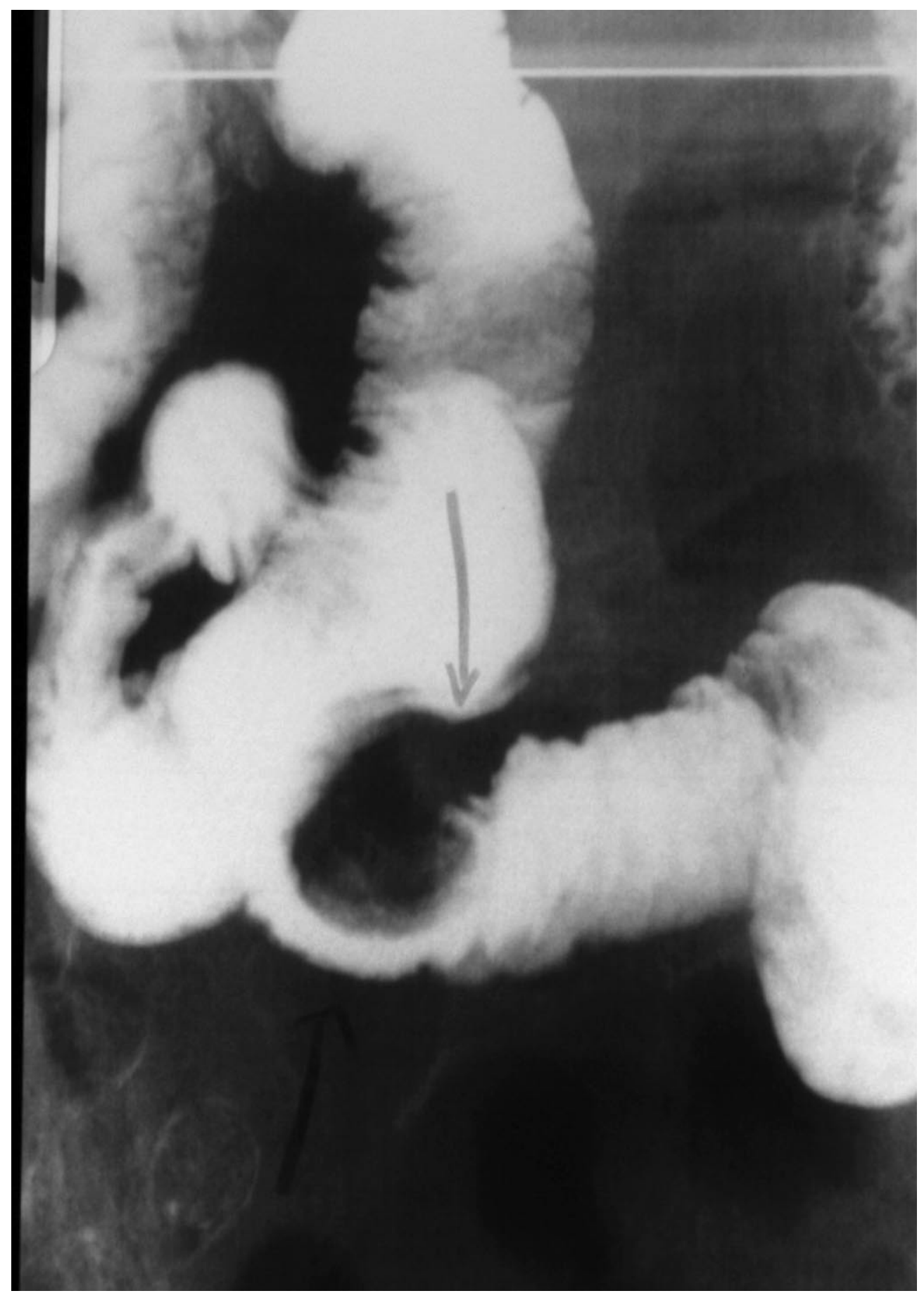

Figure 2 Barium contrast small bowel X-ray study showing marked narrowing of distal ileum lumen by primary carcinoid tumor.

On 2 January 2003 he was started on systemic chemotherapy with docetaxel as well as continuing his prior medications, increasing the i.m. long-acting octreotide to $40 \mathrm{mg}$ each month, and adding pancreatic extract to his treatment regimen.
By March 2003 he exhibited very marked improvement, having achieved a weight of $81 \mathrm{~kg}$ with no edema. His strength was very good and he insisted on returning to fulltime work, which he was able to perform without difficulty. There was no ascites, pedal edema or facial flushing. 
His blood serotonin and chromogranin-A were improved (Table 1) and a new CT scan of the abdomen showed $>50 \%$ regression of the tumors in the liver (Fig. 3). He was continued on treatment with octreotide, chemotherapy, low-dose niacin, multiple vitamins and other supportive medications.

\section{Discussion}

There are three categories of treatment employed in the management of carcinoid tumors and carcinoid syndrome. Many components of each are utilized concurrently or sequentially with their choice and timing determined by the particular and specific features of each patient's tumor and symptoms. These categories are I, medical supportive; II, surgical; and III, anti-proliferative (Table 2).

The principal component of medical therapy is the use of somatostatin analogues, octreotide or lanreotide. Other conventional and less specifically targeted anti-diarrheal medications and digestion-enhancing agents may also be used along with supportive and nutritional agents.

Although cure can only be accomplished by complete surgical excision of tumor, very prolonged palliation and

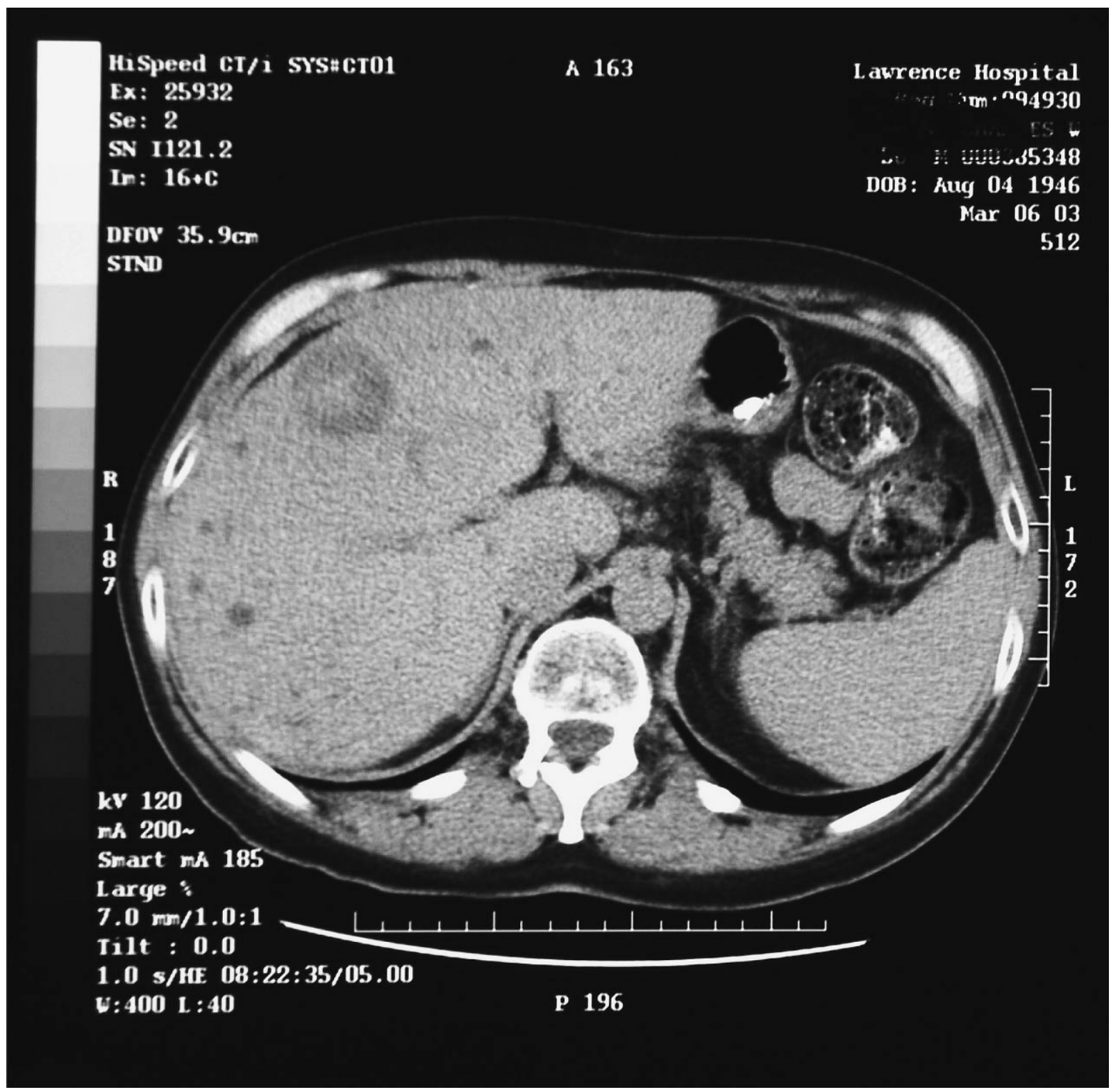

Figure 3 CT scan of abdomen following chemotherapy showing $>50 \%$ reduction in metastatic tumors in the liver. 
Table 2 Treatment of carcinoid

I. Medical supportive treatment
Anti-diarrhea drugs
Octreotide, lanreotide
Opiates, diphenoxylate, loperamide
Cyproheptadine
Cholestyramine
Pancreatic extract
Nutritional factors
Diet, supplements
Niacin
Hematinics
Electrolytes
Anti-ulcer medications
Antifrbrosis
Fish oil
II. Surgery
Biopsy
Total resection with curative intent
Control bleeding; relieve obstruction, resect ischemic bowel
Debulk tumor by resection, radiofrequency ablation,
cryoablation, embolus or chemoembolus injection
Heart value replacement
Relieve ascites - tap, shunt
Stent placement for biliary or vascular obstruction
Liver transplant
III. Anti-proliferative treatment
Biotherapy
Somatostatin analogues
Alpha interferon
Radiotherapy
Internal: ${ }^{131}$ I-MIBG, ${ }^{111}$ I. ${ }^{90}$ Y, ${ }^{177}$ Lu
Chemotherapy

survival can result from early and aggressive surgery, even when cure is not possible (Makridis et al. 1990, Norton 1994, Que et al. 1995, Chen et al. 1998, Frilling et al. 1998, Shebani et al. 1999, Chamberlain et al. 2000, Hellman et al. 2002). This often consists of removal of primary tumor and debulking metastases. Various other cytoreductive techniques are also often useful and include radiofrequency ablation (Wessels \& Schell 2001), cryoablation (Seifert et al. 1998), biological modulation (octreoscan, lanreotide, alpha interferon) (Frank et al. 1999, Öberg 2001), HACE injection (Mitty et al. 1985, Rusniewski et al. 1993, Diaco et al. 1995, Yao et al. 2001, Soulen 2002) and internal and external radiotherapy and chemotherapy (Pelley \& Bukowski 1999, Jensen 2000, Öberg 2001).

In the case presented it was apparent that severe carcinoid heart disease with congestive heart failure required urgent correction in order to salvage this patient, and before any anti-tumor treatment could be considered. Connelly (2001) points out that cardiac disease occurs in more than $50 \%$ of carcinoid syndrome patients and is the single main cause of death in carcinoid syndrome. She further notes that surgery is the only effective treatment for carcinoid valvular disease. Optimum timing for such surgery is uncertain but the presence of right heart failure in a patient with demonstrated marked carcinoid valve disease clearly indicates a need for prompt valve replacement. The observation that carcinoid syndrome patients with valve disease in general have higher serotonin levels than do those without cardiac valve disease suggests that treatment to maintain lower serotonin levels may be protective against the development of carcinoid valve disease (Denney et al. 1998, Meijer et al. 2002). The direct effect of serotonin on the valve surface appears to be the cause of the fibrous plaques that characterize this condition. This is another reason for the liberal use of octreotide in a patient with high serotonin blood levels, even in the absence of symptoms of carcinoid syndrome.

An in vitro study has demonstrated that fish oil, eicosapentaenoic acid, prevents fibroblast proliferation (a process involved in the development of carcinoid valve disease) by blocking the local effects of serotonin (Pakala \& Benedict 1995). This study has prompted me to prescribe this dietary supplement to carcinoid patients with very elevated blood serotonin levels.

Niacin supplements were included among the presented patient's medications in order to treat and prevent subclinical pellagra, a known but not generally recognized, complication of carcinoid syndrome (Fleischmajer \& Hyman 1961, Castiello \& Lynch 1972).

The persistence of moderate ascites at 1 month after cardiac surgery raised the question of whether this was being produced by peritoneal tumor exudate, lymphatic obstruction by tumor or lingering of right-sided heart failure. The finding of chromogranin-A concentration in the ascitic fluid approximately one-half that in the patient's peripheral venous blood was interpreted to indicate the persistence of a cardiac hemodynamic mechanism, rather than direct tumor exudation as the cause (Warner et al. 2002). This conclusion seems to have been borne out by complete subsidence of the ascites over the following 2 months with continued diuretic medication.

Thereafter the patient's general condition was improved enough to allow cytoreductive treatment. Since almost all of his demonstrated tumor was in the liver, HACE injection treatment was undertaken. We strongly favor HACE rather than bland embolus injection since even though a few studies suggest no added benefit by including injection of chemotherapy along with embolic material (Carrasco et al. 1986, Marlink et al. 1990, Kim et al. 1999), the preponderance of recent evidence supports HACE as producing a longer palliative effect as well as prolongation of survival (Mitty et al. 1985, Diaco et al. 1995, Soulen 2002, Warner et al. 2003). Following completion of this therapy it was considered likely that its beneficial effect could be enhanced by further tumor debulking via surgical resection and radiofrequency ablation. The survival benefit of carcinoid tumor debulking has been 
well established. Furthermore the primary tumor discovered in the ileum could be resected at this surgery along with a prophylactic cholecystectomy to avoid future cholelithiasis a well-known risk in a patient chronically treated with octreotide. This surgery would also provide the opportunity for obtaining a new biopsy of tumor of sufficient size to submit for cell culture drug resistance testing. The laparoscopic accomplishment of this surgery minimized the risk and made the procedure more tolerable for the patient.

Cell culture drug resistance testing is a relatively old technique (Weisenthal \& Nygren 2002) that has not fulfilled its initial promise for clinical benefit in managing most common malignancies but it is often useful for neuroendocrine tumors, particularly midgut carcinoids, which are usually unresponsive to most chemotherapy protocols. In this instance, based on the in vitro finding of sensitivity to a drug (docetaxel) not commonly used for carcinoid, docetaxel was administered to the patient and his tumor responded very well.

\section{Summary and conclusions}

The carcinoid syndrome case presented is an example of modest temporary benefit from conservative management, followed eventually by severe deterioration which almost precluded aggressive treatment. However, continued application of supportive measures and careful choice and timing of aggressive sequential surgery and other invasive treatment followed by chemotherapy effected marked tumor regression and rehabilitation of the patient. Although this good a response to vigorous treatment does not occur in all advanced metastatic carcinoid patients, we feel that it can occur in a significant percentage of such cases. Therefore consideration should be more often given to altering the traditional conservative treatment of metastatic carcinoid towards a more proactive aggressive approach.

\section{Acknowledgements}

This work was supported by the Carcinoid Cancer Foundation, Inc. There is no conflict of interest that would prejudice this work.

\section{References}

Carrasco CH, Charnsangavej C, Ajani J, Samaan NA, Richli W \& Wallace $S 1986$ The carcinoid syndrome: palliation by hepatic artery embolization. AJR American Journal of Roentgenology 147 149-154.

Castiello RJ \& Lynch PJ 1972 Pellagra and the carcinoid syndrome. Archives of Dermatology 105 574-577.

Chamberlain RS, Canes D, Brown KT, Saltz L, Jarnagin W, Fong Y \& Blumgart LH 2000 Hepatic neuroendocrine metastases: does intervention alter outcomes? Journal of the American College of Surgeons 190 432-445.
Chen H, Hardacre JM, Uzar A, Cameron JL \& Choti MA 1998 Isolated liver metastases from neuroendocrine tumors: does resection prolong survival? Journal of the American College of Surgeons 187 88-93.

Connolly HM 2001 Carcinoid heart disease: medical and surgical considerations. Cancer Control 8 454-460.

Denney WD, Kemp WE Jr, Anthony LB, Oates JA \& Byrd BF 1998 Electrocardiographic and biochemical evaluation of the development and progression of carcinoid heart disease. Journal of the American College of Cardiology 32 1017-1022.

Diaco DS, Hajarizadeh H, Mueller CR, Fletcher WS, Pommier RF \& Woltering EA 1995 Treatment of metastatic carcinoid tumors using multimodality therapy of octreotide acetate, intra-arterial chemotherapy, and hepatic arterial chemoembolization. American Journal of Surgery 169 523-528.

Fleischmajer R \& Hyman AD 1961 Clinical significance of derangements of tryptophan metabolism. Archives of Dermatology 84 563-573.

Frank M, Klose KJ, Wied M, Ishaque N, Schade-Brittinger C \& Arnold R 1999 Combination therapy with octreotide and alpha-interferon: effect on tumor growth in metastatic endocrine gastroenteropancreatic tumors. American Journal of Gastroenterology 94 1381-1387.

Frilling A, Rogiers X, Malago M, Liedke OM, Kaun M \& Broelsch CE 1998 Treatment of liver metastases in patients with neuroendocrine tumors. Langenbecks Archives of Surgery $\mathbf{3 8 3}$ $62-70$.

Hellman P, Lundström T, Öhrvall U, Eriksson B, Skogseid B, Öberg K, Janson ET \& Åkerström G 2002 Effect of surgery on the outcome of midgut carcinoid disease with lymph node and liver metastases. World Journal of Surgery 26 991-997.

Jensen RT 2000 Carcinoid and pancreatic endocrine tumors: recent advances in molecular pathogenesis, localization, and treatment. Current Opinion in Oncology 12 368-377.

Kim YH, Ajani JA, Carrasco CH, Dumas P, Richli W, Lawrence D, Chuang V \& Wallace S 1999 Selective hepatic arterial chemoembolization for liver metastases in patients with carcinoid tumor or islet cell carcinoma. Cancer Investigation 17 474-478

Makridis C, Öberg K, Juhlin C, Rastad J, Johansson H, Lorelius LE \& Åkerström G 1990 Surgical treatment of midgut carcinoid tumors. World Journal of Surgery 14 377-383.

Marlink RG, Lokich JJ, Robins JR \& Clouse ME 1990 Hepatic arterial embolization for metastatic hormone-secreting tumors. Technique, effectiveness and complications. Cancer 652227 2232.

Meijer WC, van Veldhuisen DJ, Kema IP, Van den Berg MP, Boomsma F, Willemse PHB \& De Vries EGE 2002 Cardiovascular abnormalities in patients with carcinoid syndrome. Netherlands Journal of Medicine 60 10-16.

Mitty HA, Warner RRP, Newman LH, Train JS \& Parnes IH 1985 Control of carcinoid syndrome with hepatic artery embolization. Radiology 155 623-626.

Modlin IM, Lye KD \& Kidd M 2003 A 5-decade analysis of 13715 carcinoid tumors. Cancer 97 934-959.

Norton JA 1994 Surgical management of carcinoid tumors; role of debulking in surgery for patients with advanced disease.

Digestion 55 (Suppl 3) 98-103.

Öberg K 1998 Carcinoid tumors: current concepts in diagnosis and treatment. Oncologist 3 339-345.

Öberg K 2000 State of the art and future prospects in the management of neuroendocrine tumors. Quarterly Journal of Nuclear Medicine 44 3-12. 
Öberg K 2001 Established clinical use of octreotide and lanreotide in oncology. Chemotherapy 47 (Suppl 2) 40-53.

Oberndorfer S 1907 Karzinoide tumoren des dünndarms. Frankfurt Zietschrift fur Pathologie 1 426-429.

Pakala R \& Benedict CR 1995 Serotonin fails to induce cellular proliferation in smooth muscle cells preloaded with eicosapentaenoic and docosahexaenoic acids. Journal of Investigative Medicine 43 (Suppl 2) 309A.

Pelley RJ \& Bukowski RM 1999 Recent advances in systemic therapy for gastrointestinal neuroendocrine tumors. Current Opinion in Oncology 11 32-37.

Que FG, Nagorney DM, Batts KP, Linz LJ \& Kvols LK 1995 Hepatic resection for metastatic neuroendocrine carcinomas. American Journal of Surgery 169 36-42 [Discussion: 42-43].

Ruszniewski P, Rougier P, Roche A, Legmann P, Sibert A, Hochlaf S, Ychou M \& Mignon M 1993 Hepatic arterial chemoembolization in patients with liver metastases of endocrine tumors. Cancer 71 2624-2630.

Seifert JK, Cozzi PJ \& Morris DL 1998 Cryotherapy for neuroendocrine liver metastases. Seminars in Surgical Oncology 14 175-183.

Shebani KO, Souba WW, Finkelstein DM, Stark PC, Elgadi KM, Tanabe KK \& Ott MJ 1999 Prognosis and survival in patients with gastrointestinal tract carcinoid tumors. American Surgeon 229 815-821 [Discussion: 822-823].

Soulen MC 2002 Chemoembolization for hepatic malignancies. 11th Annual Radiology Seminar, Oak Brook, IL, 24-26 October, 2002. http://www.miit.com/2002/abst/soulen-chemo.pdf

Warner RR, Croen EC, Zaveri K \& Ratner L 2002 A carcinoid tumor associated with chylous ascites and elevated tumor markers. International Journal of Colorectal Disease 17 156-160.

Warner RRP, Nowakowski FS, Mitty HA, Guller J, Falk A \& Sung M 2003 Outcome of hepatic artery chemoembolization (HACE) in the treatment of metastatic carcinoid of the liver. Journal of Vascular Invasive Radiology 200314 S68-S69 Abstract 198.

Weisenthal LM \& Nygren P 2002 Current status of cell culture drug resistance testing (CCDRT) http://weisenthal.org/oncol1.htm

Wessels FJ \& Schell SR 2001 Radiofrequency ablation treatment of refractory carcinoid hepatic metastases. Journal of Surgical Research 95 8-12.

Yao KA, Talamonti MS, Nemcek A, Angelos P, Chrisman H, Skarda J, Benson AB, Rao S \& Joehl RJ 2001 Indications and results of liver resection and hepatic chemoembolization for metastatic gastrointestinal neuroendocrine tumors. Surgery $\mathbf{1 3 0}$ $677-685$. 